\title{
HUGE VULVAL ELEPHANTIASIS OF UNKNOWN AETIOLOGY
}

Anjali Sethi' ${ }^{1}$, Deepak Sethi ${ }^{2}$

\section{HOW TO CITE THIS ARTICLE:}

Anjali Sethi, Deepak Sethi. "Huge Vulval Elephantiasis of Unknown Aetiology". Journal of Evolution of Medical and Dental Sciences 2014; Vol. 3, Issue 13, March 31; Page: 3324-3329, DOI: 10.14260/jemds/2014/2288

ABSTRACT: Genital Elephantiasis is an important medical problem in the tropics; usually affects young and productive age group and is associated with physical disability and mental anguish. It is one of the bizarre \& nipping diseases and has a long history of worldwide distribution. Most of the reported cases occur as an end result of lymphatic obstruction due to various diseases like Filariasis, sexually transmitted diseases (LGV \& Donovanosis) as well as malignancies. Few cases may remain of unknown etiology. We are reporting a case of huge vulval elephantiasis, etiology of which remained unknown.

KEYWORDS: Elephantiasis, Lymphatic Obstruction, Vulval.

INTRODUCTION: The word 'Elephantiasis' was originally used to describe elephant like appearance of legs. The term was subsequently used to describe the similar enlargement of arm, chest, breast, vulva, penis \& scrotum.

Genital Elephantiasis is an important medical problem in the tropics; usually affects young and productive age group and is associated with physical disability and mental anguish. It is one of the bizarre \& nipping diseases and has a long history of worldwide distribution. Most of the reported cases occur as an end result of lymphatic obstruction due to various diseases like Filariasis, sexually transmitted diseases (LGV \& Donovanosis) as well as malignancies. ${ }^{1}$

CASE REPORT: A 35 years old female was presented with a huge mass arising from right labium majus for 2 years. She noticed a small swelling over her vulva at right labium majus 2 years back. The swelling gradually increased in size over period of 2 years to reach the size of approximately $60 * 60$ centimetres. (Figures No. 1, 2, 3). The whole mass hanged from labium to reach up to knees.

The history did not reveal any symptoms related to Filariasis, sexually transmitted disease or any other disease. She had a history of surgery for excision of similar but small swelling from the same labia 5 years ago. No documental record related to previous surgery was present with patient.

The mass was non-tender, firm in consistency and had rugosities all over its surface with ulcerations at some places. The skin over supra - pubic region was also involved. The other labium was normal. Both lower limbs were normal. Inguinal Lymph nodes were not palpable. General Physical examination revealed anemia and otherwise normal.

Pre-operative investigations showed mild anemia and FNAC from the mass showed chronic non-specific inflammation. Examination of nocturnal skin prick blood sample for microfilariae was negative, Mantoux test was negative and Complete Blood Counts did not show any Eosinophilia or Lymphocythemia. After full investigations, patient was posted for operation.

After spinal anesthesia patient was placed in lithotomy position. Whole of the mass from vulva \& also from supra - pubic region was excised (total weight of the mass was approx. 8 kilograms) (Figure No. 5). The vulva was reconstructed and wound was primarily closed over a 
suction drain (Figure No.4). The drain was removed on $5^{\text {th }}$ day $\&$ sutures on $10^{\text {th }}$ day. On follow up visit, suture line was found healthy with no discharge or collection (Figure No.6).

The histopathological examination of the excised mass was suggestive of chronic non-specific inflammation.

The patient remained under follow-up for 1 year with no recurrence. There after patient did not come for follow up.

LITERATURE REVIEW: Genital elephantiasis is defined as grotesque enlargement of genitals due to lymphatic channel obstruction by various causes. 'Elephantiasis' was originally used to describe elephant like appearance of legs. The term was subsequently used to describe the similar enlargement of arm, chest, breast, penis \& scrotum. The term 'esthiomene' is applied when genital elephantiasis is associated with ulceration in vulval labia and is derived from a Greek verb which means 'to eat'. 1

Lots of etiological agents have been implicated in causation of genital elephantiasis including Filariasis, Tuberculosis, hematological malignancies, iatrogenic or dermatological diseases. Irrespective of etiology, the basic process remains the same i.e. permanent obstruction of lymphatic channels $\rightarrow$ lymphatic stasis $\rightarrow$ stimulation of growth of fibroblasts $\rightarrow$ destruction of lymph node $\rightarrow$ lymphedema \& elephantiasis. ${ }^{1}$ There is intense edema of subcutaneous tissue. The overlying skin become thick, rough \& brawny and is often dusky or purplish in colour. ${ }^{2}$ The most common form of lymphedema is secondary lymphedema. ${ }^{3}$

Globally most common cause of lymphedema is Filariasis which is caused by parasite worm Wucharia branchofti, transmitted by mosquito. In endemic communities approximately $10 \%$ of women \& $50 \%$ of men can suffer from mutilating lower limb \& genital disease. The adult worms live in human lymphatic system. Obstruction of lymphatics leads to swelling in lower limbs \& genitals. It is not definitely known whether the swelling is caused by the worms itself or by immune system in response to parasite. 4

Patients of elephantiasis associated with Tuberculosis usually have inguinal lymphadenitis. Reactive Mantoux test, suggestive histopathology, isolation of Mycobacterium tuberculosis by Polymerase Chain Reaction or culture and response to anti-Tubercular therapy are confirmatory for Tuberculosis. ${ }^{1}$

Kos M reported a case of vulvar elephantiasis which was developing since 1985 when biopsy was first performed showing only signs of chronic inflammation \& Microbiological analyses were negative. On follow up visit Serological tests to agents that usually cause vulval infections with elephantiasis were negative, and microbiological analyses revealed mixed bacterial flora. Biopsy showed again only nonspecific chronic inflammation. After 8 years of initial disease, the vulvar mass reached 16:13:10 cms and was surgically removed. The histological picture showed chronic granulomatous inflammation. The results of microbiological and serological tests were again the same as before. ${ }^{5}$

Apart from Filariasis \& Tuberculosis, STI (Sexually Transmitted Infection), constitute one of the important causes of genital elephantiasis. These STI include LymphoGranuloma Venereum \& Donovanosis. LGV is caused by Chlamydia trachomatis, the disease process primarily involves lymphatic channels. Chronic progressive lymphangitis, inguinal \& pelvic adenitis may lead to chronic 
edema, sclerosing fibrosis of subcutaneous tissue, elephantiasis and chronic genital ulceration. It is often associated with ano-rectal complications including fistulae \& strictures both in men \& women.

Donovanosis is chronic progressive destructive, granulomatous infection of superficial tissue of the genital region, caused by Calymmatobacterium granulomatis. Lymphedema of genital region is one of the long term complications. Clinically Donovanosis induced elephantiasis is characterized by firm, pedunculated, lobular swelling. It affects predominantly the labia majora \& the clitoris.

Various treatment modalities have been described for genital elephantiasis which includes compression therapy, drugs \& surgery. Basic principle of the treatment is complete removal of all affected tissue by surgery, and drugs for causative organism. ${ }^{6}$

Compression therapy is not practical for lymphedema of genitalia; but minor swelling can be treated by support hosiery.

Drugs:

LGV- Doxycycline $100 \mathrm{mg}$. twice daily for prolonged period of approx.13 months.

Donovanosis- Azithromycin $1 \mathrm{gm}$ on first day followed by $500 \mathrm{mg}$ once daily or Co-trimoxazol (Trimethoprim $80 \mathrm{mg} \&$ Sulphamethaxazol $400 \mathrm{mg}$ ) two tablets twice daily for 10-14 days.

Filariasis- Diethyl Carbazine is the drug of choice.

Bypass procedures include omentum pedicle, Skin Bridge anastomosing lymph nodes to vein; and most recently lympho-venous anastomosis with aid of microscope. However, long term results of all these techniques are poor.

Reduction procedures include removal of subcutaneous elephantoid tissue and closure of wound either by preservation of overlying skin flaps or by free skin graft or rotational flaps. Labial reduction is easily achieved by wide elliptical excision with single suture line. ${ }^{6}$

CONCLUSION: Genital elephantiasis is a significant medical problem and persons affected may become a major burden to their families \& community. At present surgery is only effective option for patients in whom the disorder is disabling, persistent and psychological devastating.

\section{REFERENCES:}

1. Surjit Nayak, Basant Acharjya, Basant Devi et al. Cerebriform elephantiasis of Vulva following Tuberculous lymphadenitis. IJDVL. 2008; 74(2): 188.

2. David M Davis. The Surgical treatment of genital elephantiasis in the male. Ann Surg. Sep 1930; 92(3): 400-404. http://www.ncbi.nlm.nih.gov/pmc/articles/PMC1398286/

3. Chintamani, JP Singh, Megha Tandon, Rohan Khandelwal et al. Vulval elephantiasis as a result of Tubercular lymphadenitis: Two case reports and a review of Literature. Journal of Medical case reports 2010. 4:369 doi: 10,1186/1752-1947-4-369.

4. Elephantiasis from Wikipedia, the free encyclopedia. http://en.wikipedia.org/wiki/Elephantiasis

5. Kos M, Ljubojević N, Ilić-Forko J, Babić D, Jukić S. Elephantiasis of the vulva of an unclear etiology: case report Lijec Vjesn. 1996 Jul-Aug; 118(7-8):158-60. 


\section{CASE REPORT}

6. Gupta, Somesh; Ajith, C; Kanwar, Amrinder J; Sehgal, Virendra N et al. Genital elephantiasis and sexually transmitted infections. Revisited. By Int J STD AIDS. 2006 Mar; 17(3):157-65 quiz 166.

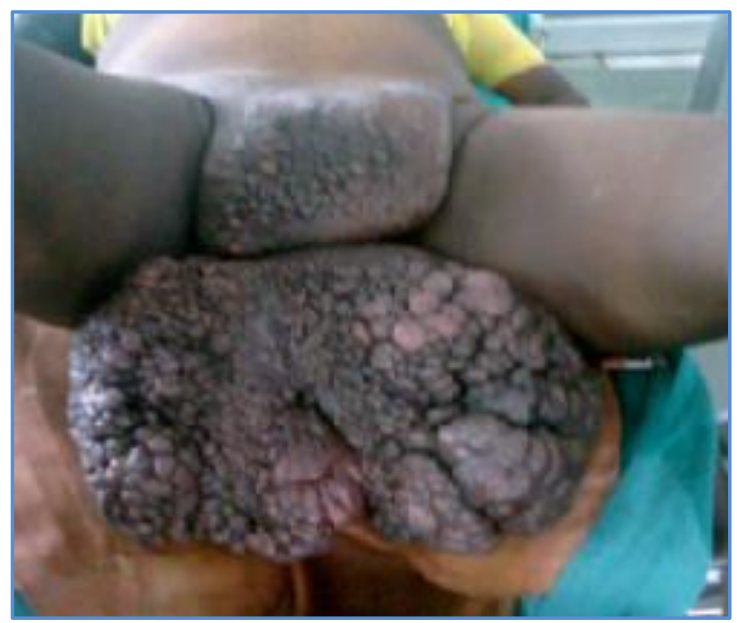

Fig. 1: Huge Vulval Elephantiasis

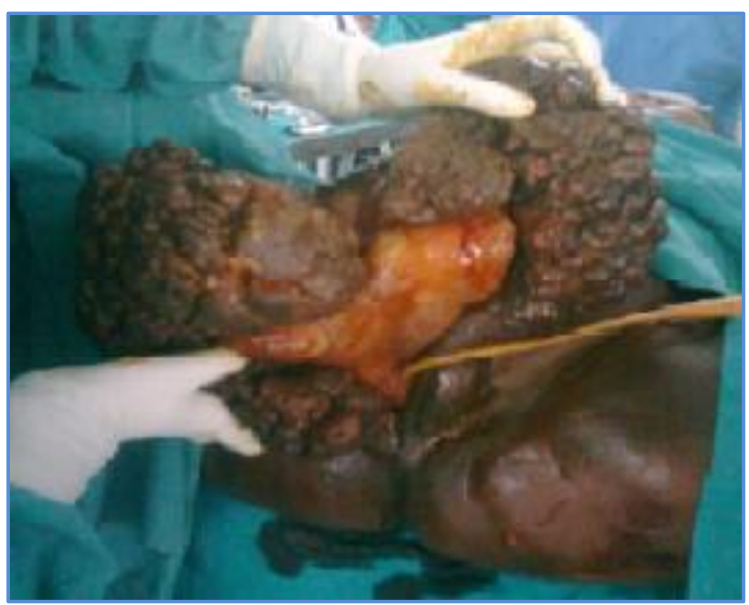

Fig. 2: Elephantiasis Involving Right labium majus only 


\section{CASE REPORT}

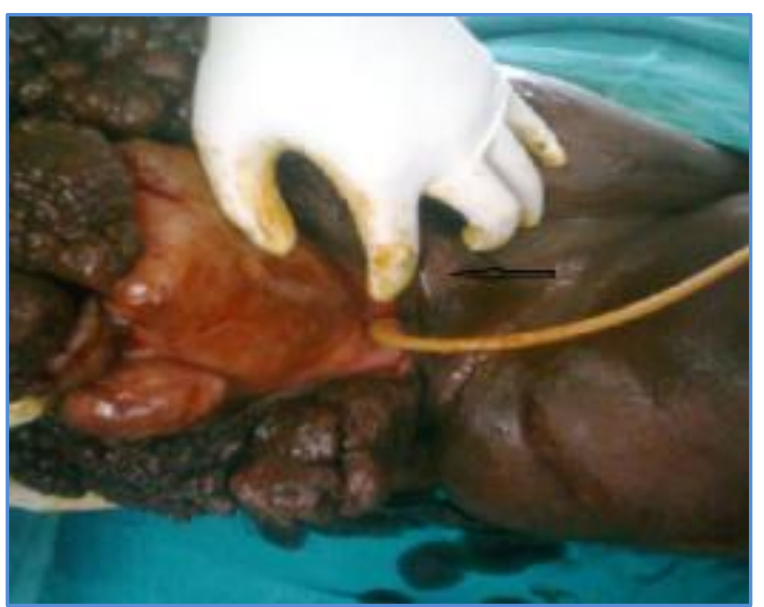

Fig. 3 : Left Labium Majus is Normal

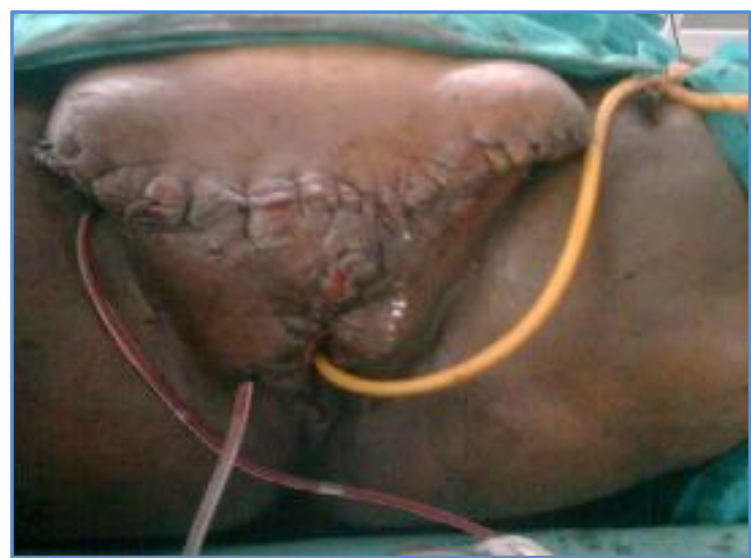

Fig. 4: Immediate Post-Operative photograph

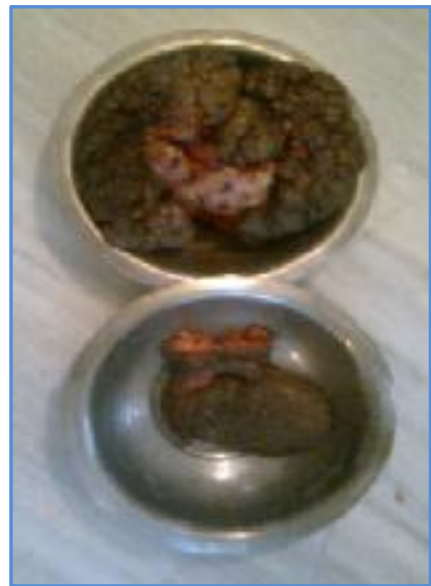

Fig. 5: Resected Elephantiasis Tissue specimen weighing approx. 8 kilograms 


\section{CASE REPORT}

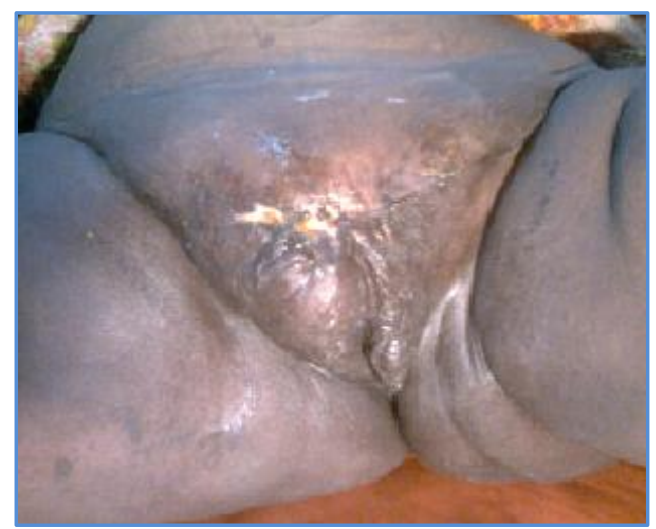

\section{Fig. 6: Post-operative photograph} After healing of wound

\section{AUTHORS:}

1. Anjali Sethi

2. Deepak Sethi

\section{PARTICULARS OF CONTRIBUTORS:}

1. Assistant Professor, Department of Surgery, R N T Medical College \& M B Govt. Hospital, Udaipur, Rajasthan.

2. Medical Officer, Department of Surgery, R N T Medical College \& M B Govt. Hospital, Udaipur, Rajasthan.

\section{NAME ADDRESS EMAIL ID OF THE}

\section{CORRESPONDING AUTHOR:}

Dr. Deepak Sethi,

303, Akshansh Apartment,

Keshav Nagar, Roop Sagar Road,

Udaipur-313001,

Rajasthan, India.

E-mail: deepanjali.d1972@gmail.com deepanjali_d1972@yahoo.com

Date of Submission: 17/02/2014.

Date of Peer Review: 18/02/2014.

Date of Acceptance: 26/02/2014.

Date of Publishing: 26/03/2014. 